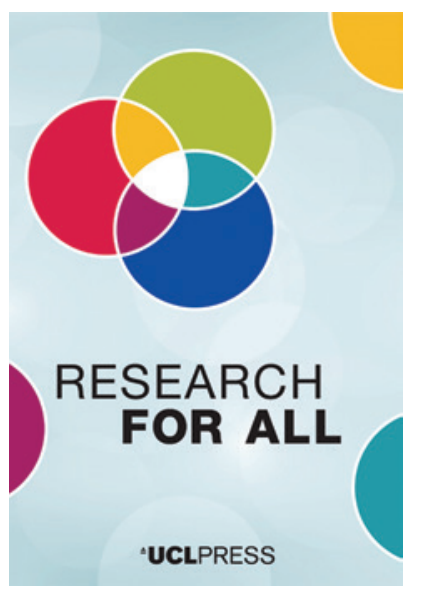

${ }^{ \pm}$CLPRESS

\section{RESEARCH FOR ALL}

The open-access journal for public engagement with research

ISSN 2399-8121 (Online)

Journal homepage:

https://www.uclpress.co.uk/pages/research-for-all

\title{
The mentoring relation as an interpersonal process in EDUCATE: A qualitative case study of mentor-mentee perspectives
}

Santiago De Ossorno Garcia (iD and Luke Doyle

\section{How to cite this article}

De Ossorno Garcia, S. and Doyle, L. (2021) 'The mentoring relation as an interpersonal process in EDUCATE: A qualitative case study of mentor-mentee perspectives'. Research for All, 5 (1), 19-35. https://doi.org/10.14324/RFA.05.1.04

Submission date: 31 October 2019

Acceptance date: 28 October 2020

Publication date: 16 February 2021

\section{Peer review}

This article has been peer-reviewed through the journal's standard double-blind peer review, where both the reviewers and authors are anonymized during review.

\section{Copyright}

(C) 2021 De Ossorno Garcia and Doyle. This is an open-access article distributed under the terms of the Creative Commons Attribution Licence (CC BY) 4.0 https://creativecommons.org/ licenses/by/4.0/, which permits unrestricted use, distribution and reproduction in any medium, provided the original authors and source are credited.

\section{Open access}

Research for All is a peer-reviewed open-access journal. 


\title{
The mentoring relation as an interpersonal process in EDUCATE: A qualitative case study of mentor-mentee perspectives
}

\author{
Santiago De Ossorno Garcia* - UCL Institute of Education, UK \\ Luke Doyle - Founder of SwopBots, UK
}

\begin{abstract}
The EDUCATE research-based accelerator employs academic mentors to support entrepreneurs to use research in the development of educational technology. Mentorship is a common feature of business accelerators, yet only a few empirical studies have shown or analysed the relationship and how it influences business success outcomes. In EDUCATE, the mentorship adopts a unique approach by focusing the relationship on goals and evidence-based knowledge exchange concerning educational technology. Examining previous literature on mentorship and exploring the novel features of EDUCATE, a qualitative case study was conducted using a semi-structured interview with a mentor and mentee within the programme. Although this was a limited study of only one dyad mentor-mentee relationship, the research elicits findings that may be of interest for future research. The study highlights the importance of the interpersonal process of mentorship, and advances understanding of what constructs effective mentorship relationships for accelerators. Findings suggest that from the perspective of the mentee, the psychosocial function forms a big component of the relationship. Concepts such as trust, decisionmaking, personality and self-efficacy arise in the analysis. In contrast, the mentor focuses on career functions and aspects of the programme such as frequency of interaction and knowledge about research. In addition, structured goals within the relationship seem to help the research activities expected in the accelerator. In conclusion, mentorship within EDUCATE is key for the programme, the psychosocial functions in the relationship are critical for entrepreneur satisfaction and, consequently, the integration of research and practice. Constructs such as trust and personality are worth exploring as components within training of the psychosocial aspect of mentors' activity, as opposed to the traditional view of expert and experienced mentors, often acquired in business accelerators. The analysis of the interpersonal process is of importance to further understand the definition of 'good mentor' within formal mentoring programmes for evaluation purposes.
\end{abstract}

Keywords: mentorship, accelerators, educational technology, interpersonal processes, knowledge exchange 
Key messages

- The quality of the mentor-mentee relationship is a key factor in the success of the EDUCATE programme. This case study identified psychosocial functions as the most salient to the mentor-mentee relationship being studied.

- The focus on shared goals, including creating a logic model and research plan, became a key part of the relationship, building trust and understanding.

- The mentor relationship may act as a broker of knowledge exchange, facilitating integration of research and practice.

\section{Introduction}

Mentorship is a common feature of business accelerators for start-ups and small and medium-size enterprises (SMEs), yet few empirical studies have shown the positive relationship between this often formal, relational phenomenon and the business success metrics and outcomes for an accelerator. Some scholars position the mentorship feature as a fundamental component of accelerators and incubators (Fishback et al., 2007). In EDUCATE, the mentorship takes a unique shape by focusing the mentor relationship on the goals and content of research protocols and evidence-based knowledge exchange. Additionally, the mentors, who come from an academic background, consider the entrepreneurs' own context and dynamic business situations in the relationship. A detailed focus on the interpersonal processes of mentorship and its components is needed to make sense of the relationship between these processes and the intended success outcomes (from the business perspective) for engagement within the EDUCATE accelerator. Building on existing research on mentorship, and exploring the novel features of this unique relationship for the EDUCATE accelerator, this preliminary qualitative study looks at the distinct and common features of mentorship using the two perspectives of the relationship (mentor-mentee). This aims to elucidate the importance of the interpersonal process and advance our understanding of what features may define a good and effective mentor for research-based accelerators such as EDUCATE.

\section{Mentorship as an interpersonal process}

We can trace mentorship back to classical history embodied in Greek myths, such as the Homer's Odyssey (Ragins and Kram, 2007). Currently, there is extensive research literature on this particular developmental relationship, often referred to as a one-toone relationship between a less experienced (the mentee) and a more experienced person (the mentor). This relationship is a focus for providing personal and professional growth to the mentee (Mullen, 1994). Zachary (2002) explores the relationship in his research within educational settings, concluding that mentoring passes on knowledge of subjects, facilitates personal development and encourages wise choices. The mentor also helps the mentee to make career transitions. Nowadays, one could argue that the mentoring process is grounded in Bandura's (1977) social learning theory, which states that individuals learn through observing the actions and behaviours of influential role models.

However, a common definition for mentoring is difficult to achieve, as it tends to have different meanings for people (Kram, 1988). Scholars studying mentoring over the last thirty years have accrued some understanding about this phenomenon and the factors that contribute to this particular kind of interpersonal relationship. 
In the seminal work of Kram (1980, 1988), mentoring research traditionally describes mentorship as serving two main functions: career functions and psychosocial functions. The career functions often relate to mentorship within the workplace or academic institutions, and focus on the career development of the mentee. These functions relate to networking, coaching, protecting and challenging work practices of the mentee. Additionally, mentors tend to offer support in career progression. The psychosocial aspect of mentorship entails role modelling, acceptance and counselling relating to the mentee's sense of competence, effectiveness and self-worth. However, more recent mixed-methods research involving a sample of more than two hundred mentors and mentees identified up to eight components/functions: personal and emotional guidance; coaching; advocacy; career development facilitation; role modelling; strategies and systems advice; learning facilitation; friendship and function (Fowler and O'Gorman, 2005).

The dyadic structure of this interpersonal relationship is formed by two agents (mentor and mentee), but the research rarely examines this from both perspectives (Wanberg et al., 2003). The research literature sheds some light on the effects of gender and diversity (Scandura and Williams, 2001; Chandler and Ellis, 2011), effectiveness factors (Seibert, 1999), outcomes (Ragins and Cotton, 1999) and components of mentorship (Allen and Eby, 2003; Allen et al., 2006). Some research focuses on the quality of the mentor-mentee relationship, explaining the underpinning factors, including the mentor's and mentee's personal and professional qualities (Rippon and Martin, 2003), their skills and practices (Hall et al., 2008), the context in which the mentoring operates (Forsbach-Rothman, 2007), and the selection and matching of mentors and mentees (Hobson et al., 2009). More recently, some studies have linked personality as an individual characteristic to improve effectiveness in formal mentorship programmes (Bozionelos et al., 2014; Menges, 2016). Further qualitative studies also look at the influence of trust (Erdem and Aytemur, 2008), and the continuum between dysfunctional and functional relationships, highlighting the importance of interpersonal skills in order for mentors to articulate pedagogical knowledge effectively to their mentees (Gormley, 2008).

Other studies identify and compare different types of mentoring, such as formal and informal, with evidence leaning more towards effectiveness for informal mentoring (Blake-Beard et al., 2007; Turban and Lee, 2007) due to the mutual attraction already established in the relationship. Formal mentoring is guided by an organization (third party) that establishes a programme and process for mentoring. Often, formal mentoring relationships are short term, and mentors and mentees are paired by the organization or programme rather than organically matched, which does little to help ensure interpersonal compatibility (Ragins and Cotton, 1999). An interdisciplinary meta-analysis was conducted between different formal mentoring programmes, highlighting the benefits of the frequency of meetings and the quality of these interpersonal relationships (Eby et al., 2013).

In the context of SMEs, being a mentor to a person who is starting up a business is more likely to occur through a formalized programme rather than an informal connection (Hofman, 1998), such as within a start-up accelerator.

\section{Mentorship in accelerators}

Accelerators are short-term programmes (3-6 months) for new ventures to support the SMEs in their early stages. Business accelerators provide entrepreneurs with a wide range of opportunities for innovation in their industry (Miller and Bound, 2011). These programmes often provide a set of services and support for early-stage entrepreneurs, 
such as office spaces, formal coaching and mentoring, access to small amounts of financial support and structured educational programmes.

Although they are a relatively new phenomenon, accelerators have accrued interest from the private and public sectors, and are often a common instrument of support for start-ups to engage with. Accelerators were first observed in the early 2000s, and since then the accelerator concept has expanded to become an important part of the entrepreneurial and start-up ecosystem (Cohen, 2013). Since their inception, accelerators have included mentoring in their structure, as accelerators were conceived and often established by experienced and successful entrepreneurs who mentored and guided start-up ventures with the intention of reducing high failure rates $\left(\mathrm{O}^{\prime} \mathrm{C}\right.$ onnell, 2011).

Mentoring within accelerators appears to be a fundamental part of the accelerator structure, often linked with their educational programmes (Cohen and Hochberg, 2014; Pauwels et al., 2016). However, mentorship in the accelerator setting is unique and different from other mentorship processes in research literature (Chandler et al., 2011). There is limited evidence and empirical understanding of how these relationships should work, and a lack of systematic evidence to show that new ventures that do invest in accelerators experience improved early-stage venture outcomes (Mejia and Gopal, 2015). Yitshaki and Drori (2018) identify three main educational tasks of these mentoring roles within the accelerator context: (1) sharing knowledge and experiences related to their field of expertise; (2) providing advice on recurring dilemmas and strategies that require knowledgeable understanding of the issues involved; and (3) exposing mentees to the social networks of mentors. Mentors in accelerators attempt to provide entrepreneurs with tacit knowledge, consequently serving as agents of the relationship that contribute to the spread of information and knowledge transfer (Gaba and Meyer, 2008). These authors conducted the first empirical attempt to understand the processes underlying an accelerator model by immersing themselves in one. They found that entrepreneurs and early-stage ventures needed to bring an existing idea to the accelerator, and to embark on a continuous iterative cycle of stating, testing and refining a target opportunity. Mentors play a key role in the process of identifying mentees' opportunities by providing feedback on the existing idea and by providing access to expert information, to further refine or change the idea into a similar but different area.

This iterative process resembles the scientific method for research across disciplines of hypothesis formulation, empirical testing and reformulation. In relation to educational technology, this can be compared to the short-cycle research and human-centred design practices often used in the field.

These ideas are combined in the EDUCATE programme, where mentors, who are academics, aim to transfer knowledge in research and education to the entrepreneurs, seeking to build or improve their educational technology ideas, products and services. As summarized by Gaba and Meyer (2008), mentors in an accelerator can affect entrepreneurial outcomes by increasing the amount of information to identify opportunities and the tacit information available to aggregate resources in a venture. However, this influence on outcomes seems to occur through the relational interpersonal process of mentorship, which involves a close relationship between an entrepreneur and an academic expert in social sciences research. In the case of EDUCATE, this relationship aims to bridge the concern around why research on technology has failed to produce evidence that it makes a difference in the teaching and learning process (Lagrange et al., 2001; Schrum et al., 2005; Roblyer and Knezek, 2003). It also empowers entrepreneurs to conduct applied research about their educational technology solutions and to grow their companies in an evidence-informed manner. 


\section{Research mentorship at EDUCATE research-based accelerator}

Mentorship is an important feature of the EDUCATE programme (Cukurova et al., 2019). Each participant in EDUCATE is mentored by an academic researcher employed by the programme to enable the participant to conduct and use research on their educational technology innovation. There is no strategic matching, and mentors are allocated to a number of participants over a six-month period. In the first three months, there are scheduled one-to-one confidential meetings, known as 'clinics'; the second three months are composed of less structured 'ad hoc' support to enable entrepreneurs to conduct applied research, advise about research methods in social sciences and look at data collection practices, pedagogical principles and research biases.

The role of the mentor at EDUCATE is to:

- help the entrepreneurs to define specific research goals for their organization

- support the mentee to achieve these goals and manage their expectations around them

- enable the entrepreneur to define their product or service through the 'theory of change'

- use a logic model as a collaborative tool, in order to define the context and intended impact for their product and services

- enable the mentee to develop a research proposal in line with guidance and resources provided in the research training.

The mentor at EDUCATE needs to build a relationship with the mentee. They collaborate and support the creation of a 'theory of change' specific to the product or service that the participant brings to the programme. The theory of change (Lewin, 1947) enables EDUCATE participants to articulate the theories that underpin their products into a measurable framework of evidence and research. It also enables the development of a time frame to evaluate changes in the users of the educational technology.

EDUCATE also uses a programme evaluation framework (W.K. Kellogg Foundation, 2004; Zhao et al., 2008), also known as a 'logic model'. This collaborative object of the relationship helps the entrepreneur to materialize the theory of change and test ideas within a framework, in order to evaluate their solution. The logic model is a flowchart process that looks at the intervention through the lens of impact, intending to describe the desired changes at the societal/contextual level. It is divided into five components (inputs/resources, activities, outputs, outcomes and impact), allowing the entrepreneurs to conceptualize research on their solutions from design to implementation, and researchers to collaborate and share a common language and enable research that can evaluate their solutions while accounting for the development stage of their technology.

The last output from this relationship and the EDUCATE programme is a research proposal. The research proposal serves as a plan of action for the entrepreneur, in order to test ideas and hypothesize about their educational technology product or service, within an applied research perspective.

The aim of this case study research is to:

- present the perceptions of the mentee and the mentor relationship

- show how the objectives of the EDUCATE accelerator were achieved through the knowledge exchange, by bridging the gap between research and practice for the educational technologist 
- describe the activities occurring in this six-month formal mentoring relationship

- explore the interpersonal processes informed by previous mentorship research literature.

These aims form the overaching research question that underpinned all the qualitative analysis conducted: How and which key features of the mentorship interpersonal processes literature are salient in an EDUCATE mentor-mentee relationship? These preliminary findings will serve as an initial framework to explore further data on the mentorship process, to inform accelerator mentorship programmes and to improve the EDUCATE mentorship provision in the future.

\section{Method}

In order to inform this qualitative case study, a semi-structured interview was developed by the researcher. This was then reviewed by other mentors, with the aim of understanding the mentorship relationship, and the main technical components and collaborative objects used throughout this relationship (logic model, theory of change and research proposal). Independently, the mentor and the mentee answered the questions of the semi-structured interview. The answers to the semi-structured interview were collected through email and transcribed. The coding process used a hybrid inductive and deductive approach (Fereday and Muir-Cochrane, 2006). The deductive approach used an a priori developed 'codebook' containing previously identified themes on mentorship relationships literature following King's (2012) stepped processes. The inductive approach allowed specific EDUCATE mentorship themes to emerge from the data. Finally, a reflective synthesis combined the identified themes commonly used in mentorship research and specific themes particular to the EDUCATE programme. A final analysis was conducted to identify the role of the different meanings of this interpersonal relationship, considering each participant's perspective.

Mentor and mentee perceptions are a key component to understand this interpersonal process. Such research is repeatedly called for in formal mentoring research literature, but has seldom been conducted (Wanberg et al., 2003). Understanding the EDUCATE context and specific features of the programme is important for examining how the mentorship relationship acts as a brokerage of knowledge, bridging the gap for the educational technologist between theory and practice within the accelerator context. The findings of this case study should not be formally generalizable, but they could be transferred to other mentoring relationships and future implementations of similar accelerator programmes.

\section{Participants}

The mentee and mentor volunteered to participate in and conduct the study in collaboration. Throughout the six-month formal relationship, the mentee focused the research interests on creating a new product; his research focused on participatory design workshops for video game creation and design, involving a classroom of diverse special educational needs.

Mentee: Luke Doyle qualified as a UK teacher in 2000. In 2011, he set up a small free school in Bangladesh, with the aim of teaching basic computing skills to young people to help them find well-paid employment in the IT sector. In 2017, Luke released SwopBots, a coding game for children aged 8 to 11 based on 'scratch language'. The game was based on his own experience of teaching coding to children with no 
prior computing knowledge. Luke initially applied to EDUCATE with his first product. However, he realized that there had been a lack of user feedback during the development of the software. This realization encouraged Luke to engage with EDUCATE and the mentorship programme, in order to learn more about using research-based evidence to create more effective products for students. Having begun with EDUCATE, Luke had a discussion with a local special educational needs school. It became apparent that the school was struggling to find appropriate software to teach computing to some of its students. Luke decided to use his time with EDUCATE to work alongside the school and its students to develop a new product that could help to address some of these needs.

Mentor: Santiago De Ossorno Garcia qualified as a psychologist in 2012. He obtained postgraduate qualifications in health psychology, psychological therapies and methodologies for health and social sciences. His research expertise is in educational policy, psychometrics and developmental psychology. He is one of the research mentors at the EDUCATE project, supporting entrepreneurs who are developing educational technology, including Luke. He is a trained psychotherapist in Spain, with practical experience in the UK supporting community mental health outreach projects.

\section{Semi-structured interview}

The interview was developed by the first author, and reviewed by other mentors within the EDUCATE project. One mentee also agreed to review the original questions, which were adapted following feedback. The final interview was composed of eight openended questions:

1) What are the benefits of the research mentorship relationship in EDUCATE?

2) What were the challenges?

3) What are the main factors that contributed to or hindered your relationship with your mentor/mentee?

4) Did the theory of change for their/your product or service help to conduct appropriate research? If yes, how? If not, why not?

5) Has the logic model helped you/them? If yes, how? If not, why not?

6) What role/s did the research proposal play? If more than one, please explain how; if none, please justify.

7) What other part of your/their participation at EDUCATE helped you/them in the development of your/their products or services?

8) In your own words describe the mentorship relationship at EDUCATE (for example, how did you feel about the relationship? What is your opinion of the relationship? What did you do?).

The interview length was two hours for each participant.

\section{Findings}

From the transcripts of both interviews, some themes, topics and constructs familiar from the previous literature on mentoring emerged while the coding process took place. In these sections, the findings are described based on the initial functions (career functions and psychosocial functions) and the main hierarchical themes deductively identified, supported by excerpts from the transcripts and narrative synthesis of the relationship and case study. A final inductive theme arose from the 
analysis on the programme-specific functions, which is discussed in relation to the collaborative artefacts of the programme and their impact on the relationship. The mentee and mentor analysed their dyadic perspectives differently. Due to the number of mentorship relationships with which they are engaged, the mentor is expected to have a more general understanding of the type of relationship as it is experienced in the role. On the other hand, the mentee forms his narrative from the interview for the specific formal mentor relationship experience on EDUCATE. However, the analysis found that the mentee had engaged previously with other formal mentorship programmes in accelerators.

\section{Psychosocial functions}

From all the analysis, the most salient and frequent function relates to the psychosocial function of mentorship. This is described as a process that encompasses the interpersonal aspects of mentoring (Kram, 1988), which produces a sense of self-efficacy in both parties. Often, role modelling is acknowledged as part of the interpersonal process in these functions. This also resonates with the role of coaching within the mentorship, providing motivation and goal orientation within the programme. It helps the mentee to learn about appropriate attitudes, values and behaviours in the programme. In this relationship, the mentor shows some understanding about this process, but the impact on the mentee's sense of selfefficacy and development of competencies and experiences of self-discovery is also evident in the excerpts:

\section{Mentor:}

Mentors hold a set of values that may interact with the mentee in the relationship.

He also showed dedication towards accessibility and vulnerable groups, this aligned with my personal values and expertise, therefore I felt that the relationship was very positive.

I felt quite positive since the first session. He presented with confidence and dedication to his venture ... The motivation of the mentee to receive advice can be energizing.

\section{Mentee:}

It was more about what he could do in my situation rather [than] what I can do in my situation.

It also helped me to understand my own strengths and weaknesses.

I had to hand over a lot of control ... quite scary!

Interpersonal processes in mentoring often resemble counselling skills; this enables the mentee to develop a positive sense of self. In the interpersonal process of counselling, trust is essential to establish rapport and closeness in the relationship (Hutchinson et al., 2017).

Through processes of acceptance and confirmation, the interpersonal process allows for the mentor to have unconditional positive regard for their mentee (Stokes, 2003). In alignment with previous qualitative research in mentorship relations (Erdem and Aytemur, 2008), the mentee in the case study mentioned trust as a construct repeatedly throughout the interview: 


\section{Mentee:}

I changed my original plans. This can only happen successfully if you trust in your mentor.

Lots of people will give you advice, but when advice challenges your own perceptions, it needs to come from someone whose opinion you trust.

I definitely trusted my mentor and valued his opinion.

Finally, there is an element of feeling understood by the mentor, reported by the mentee. The mentee talks about this in relation to the construct of personality. The mentee had experienced a previous mentorship relationship, with some negative feelings arising from the previous mentor's lack of ability to understand the mentee's situation and abilities. Some authors have speculated and explored the importance of the personality variables in organizational settings (Menges, 2016):

\section{Mentee:}

I felt he completely understood my situation and understood my personality. He challenged me just enough to push me out of my comfort zone and set realistic goals.

I had worked with a business mentor before. This relationship had been a disaster ... my mentor had not really taken the time to understand my particular situation and gave generic advice ... he told me what I was doing wrong and expected me to act, even if I didn't have the skills to do so.

Another theme which arises from the analysis is decision-making and change within the relationship. Gehrke and Kay (1984) reveal that mentors were influential in their mentees' decision-making. In EDUCATE, mentors are required to adapt to the everchanging circumstances of entrepreneurs and to avoid an autocratic approach to the role. In relation to the mentor function, Yitshaki and Drori (2018) state that in the relationship, the mentor provides advice on recurring dilemmas and strategies that require knowledgeable understanding of the issues involved:

\section{Mentee:}

Listening to the ideas from my mentor, I changed my original plans.

I had to re-evaluate my whole approach to the project I had in mind ... I kind of wanted to launch into thing[s] and get on with it straightaway.

\section{Mentor:}

Using gentle challenge and inquiry, as opposed to directive tasks or imposition of ideas and routes for research.

Situations of their business changed quickly in parallel with the [EDUCATE] research goals [for the mentee] and time for the programme.

\section{Career functions}

Whereas in traditional research literature the career functions of mentorship are related with organizational and career outcomes, in the context of EDUCATE these functions resemble the line of research on undergraduate mentorship programmes for higher education (see Pfund et al., 2016). In this analysis, these career functions were 
related to the concept of knowledge transfer or exchange (Argote and Ingram, 2000). Due to the research-specific tasks of EDUCATE, many of the excerpts relate to the research skills proposed by Pfund et al. (2016) in her review of mentorship attributes in the relationship. From the mentee's perspective, the research process allowed for reflection and analytical thinking, whereas the mentor attached more importance to the diversity of knowledge required to cover a multidisciplinary approach to research, resources and ethical issues in the relationship:

\section{Mentee:}

It was also a challenge for me to slow down and read through research papers.

This is helping even if you end up rejecting the new ideas, because at least you have gone through the process of considering alternatives and then rejecting them based on more careful consideration.

\section{Mentor:}

Dealing with different disciplines, unknown theories, or technological paradigms that the expert is not familiar with can create some anxiety in the mentor advising.

Dealing with confidentiality, potential conflict of interest or lack of expertise in the area I felt could make the relationship difficult.

At times, it may be very difficult to manage the feasibility of study thinking of the amount of resources that a small enterprise can afford.

\section{Programme-specific functions}

The last theme identified from the analysis relates to context-specific themes within the EDUCATE programme, in particular the objects of collaboration that take place in the mentorship relationship, such as the logic model and research proposals. The analysis shows the influence of the logic model and research proposal as a fundamental aid in the relationship:

\section{Mentor:}

A [logic model] collaborative tool that helps to specify outcomes and further ideation for new features and development of their products ... Challenging these assumptions can open up curiosity and further improvements in the product. It allows the translation of business terminology and research terminology into the same object.

\section{Mentee:}

Going through the formal process of writing the logic model was helpful. I now have a clear idea of what I want to do ... the logic model encouraged me to think of alternatives to that.

Logic models are an essential tool for understanding, implementing and evaluating evidence-based programmes (Moyer et al., 1997). Millar et al. (2001: 74) describe the usability of logic models as 'useful to any person trying to plan, manage, account for, audit, evaluate, or explain the connections between what a program requests in terms of resources and what it seeks to accomplish'. In the relationship between the mentor and mentee, the logic model was used as a boundary object, as intended in EDUCATE, 
to identify clearly their own causal reasoning about an intended process occurring in the educational intervention, and to conceptualize and enhance credibility through evidence of change (Laverack and Wallerstein, 2001). It also appeared to help with planning and reflection on different alternatives and causal paths for their educational technology intervention. The mentee did two iterations of the logic model, across three months, looking at participatory design workshops as an intervention to generate evidence for his prototype. In this sense, the aim of the logic model seems to match literature that states that the logic model helps to clarify goals and relationships within the intervention, to strive for consensus (between mentor and mentee), to identify gaps in knowledge, to explore alternative approaches, and to provide an analytic framework (Kaplan and Garrett, 2005; Millar et al., 2001).

Below are the excerpts that mention the research proposal and how it was perceived within the relationship:

\section{Mentor:}

This [theory of change] helps them to understand key outcomes that they would like to explore and analyse in terms of research ... [The research proposal] helps with the relationship and the ownership of the mentee and their research goals.

\section{Mentee:}

The research proposal was extremely important and useful. I was forced to think carefully about the steps I would take, as well as the wording used to convey my plans to others.

The research proposal helps with specific research skills. In their review of undergraduate mentorship programmes, Pfund and colleagues (2016) identified research skills as one of the main attributes of effective mentorship relations. Within those attributes, teaching disciplinary research skills, or technical skills, emerged as a theme in the interviews, in addition to research skills such as valuing and practising ethical behaviour and responsible conduct of research. The mentee expressed how the proposal allowed him to convey plans about his research in the school. The research proposal helps with these specific research skills in EDUCATE, due to its research focus. The formal mentorship programme resembles a mentorship undergraduate programme, as similar outcomes are pursued in relationship to research outputs and academic goals. The research proposal also seems to resonate with one of the four phases of mentoring - initiation, cultivation, separation and re-definition (Kram, 1983). These phases describe the different stages of a mentorship relationship from a temporal perspective. However, they are not covered in this research due to its retrospective nature. Nevertheless, it seems that the four stages proposed by Kram (1983) may be of interest in understanding mentorship through the interpersonal lens in future research.

\section{Conclusion}

The overarching aim of this research was to examine the interpersonal processes and describe the activities of a mentorship relationship at EDUCATE using a retrospective qualitative approach, while considering the dyadic perspectives on the relationship. The research question explored how and which key features of the mentorship interpersonal processes literature are salient in an EDUCATE mentor-mentee relationship.

Previous mentorship literature was examined in the narrative analysis to explore the correlates with the mentorship at EDUCATE. It seems that the initial differentiation 
proposed by Kram (1988), who identified two main mentorship functions, matches the thematic analysis conducted for the interviews. Three main themes were identified: career functions, psychosocial functions and programme-specific functions. The data from this case study identified the psychosocial functions as the most salient in the relationship, highlighting the importance of trust, in line with the findings of previous qualitative research on mentorship (Erdem and Aytemur, 2008). Understanding personality and provoking change were also processes that were accounted for in the analysis, for example, counselling interpersonal processes such as active listening and gentle challenge. This relates to some studies looking at mutual attraction in the mentor-mentee dyad, which results in higher trust and psychological safety, deemed critical to nurture the relationship (Armstrong et al., 2002; Chun et al., 2010). This also relates to the concept of personal congruency identified as an effective characteristic for formal mentorship programmes (Nottingham et al., 2017). Psychosocial, intellectual and emotional support are functions that other researchers have highlighted when analysing formal mentorship programmes focused on enabling research outcomes for undergraduate students (Thiry and Laursen, 2011; Abedin et al., 2012).

Traditionally, the only experience required for being a mentor is having been mentored, regardless of whether the experience was negative or positive (Handelsman et al., 2005). However, in the context of this study and EDUCATE, interpersonal skills and alignment between mentor and mentee are components required for enablement of a positive relationship, as opposed to the technical skills and experience in research that mentors already hold in their roles. This suggests, as recommended (Kram, 1988; Cunningham, 1993), that future training for mentors should enhance the quality of mentorship and the psychosocial aspects of the relationship, and that counselling skills and interpersonal competencies for mentors should not be overlooked. Using instruments to align mentor-mentee expectations has also been recommended, as well as instruments that can help to monitor the goals and the relational process itself, improving the understanding of interpersonal processes (Hamlin and Sage, 2011).

The career functions of the relationship show the importance and primary goal of knowledge exchange and transference of knowledge. MacArthur (2014: 117) explored the mentoring role in a health setting to enable nurses to become practitioner-researchers; as described in her research, 'mentors fulfil a crucial role brokering the worlds of research and practice and need to be able to tailor their support to individual needs'. A similar process and practical implications for the mentor are highlighted here - the mentor seems to balance out the theoretical knowledge provided to fit the individual needs of the entrepreneur. Furthermore, a careful consideration around the anxiety towards the components of the formal relationship and expertise was documented, which links with previous studies that integrate the attachment theory in mentorship (Scandura and Pellegrini, 2004; Germain, 2011). The mentee seems to acquire some technical skills, such as analytical thinking, academic reading and self-efficacy for research; these skills are related to Pfund's (2016) framework for assessing mentorship relationships. Some of the attributes and functions for the measurement of the relationship are feasible for implementation in EDUCATE, and they can serve as a theoretical framework for future thematic analysis of the mentor-mentee relationships. The authors describe that mentees and mentors engage as partners through reciprocal activities such as planning, acting, reflecting, questioning and problem-solving (Pfund et al., 2016). These activities are part of the processes described in the programme-specific functions when mentor and mentee describe the use of the logic model and research proposal.

As proposed previously in the field of mentorship research, it seems that in order to explore and evaluate this relationship in the context of accelerators and formal 
mentorship programmes, the analysis of both perspectives should be considered (Wandberg et al., 2003). It is clear from the findings that the perspectives in the relationship are different; however, thematic analysis based on mentorship frameworks is feasible to explore commonalities and differences that can describe and inform the relationship. Dempwolf and colleagues (2014) highlight in their report that accelerators do not always work in practice the way that we think they might in theory. There are many factors that affect the success and viability of start-ups; therefore, understanding the mechanism by which accelerators provide value beyond the initial seed investment is of critical importance to assess the impact of the mentorship aspect of accelerator programmes such as EDUCATE (Cohen and Hochberg, 2014).

Our data suggest that in order to evaluate and explore mentorship-based accelerators, further research should look at the assessment of the quality in relationship. This requires measuring both the mentor's and the mentee's perceptions of important dimensions of the relationship, such as goals, engagement and closeness, rather than data collected only at the programmatic or administrative level (Lunsford et al., 2017).

Mixed-method approaches to the mentorship relationship in accelerators can be of use to produce further evidence and evaluation for effectiveness and impact studies (Creswell et al., 2003; Greene et al., 1989). Deutsch and Spencer (2009) propose an assessment framework for mentoring programmes that can be transferred to, and tested in, the accelerator context. They propose cross-sectional surveys or interviews, using both validated measures and open-ended questions, which may be used as tools for assessing individual relationships at the conclusion of programmes. Mejia and Gopal (2015) use the multidimensional mentoring instrument MFQ-9 (Scandura and Ragins, 1993) in their accelerator empirical study. In addition, short surveys, logs and observations may be useful for periodic or ongoing assessment of quality of support and intervention purposes within the programme, to allow mentorship improvement, reflective practice and personal development for mentee and mentor.

Our study suggests that this type of assessment framework may be feasible by looking at the transcript sessions of mentorship clinics collected in EDUCATE. This will allow a thematic analysis following mentioned frameworks and tools, to investigate the constructs and inform the outcomes for the evaluation of a mentorship programme within an accelerator.

\section{Limitations and future research}

The nature of this case study research implies that the results of this study cannot be generalized to the wider population. This study only analysed one dyad relationship, with only one interview per participant, highlighting the small scale of the data collection. Hence, findings should be interpreted carefully and replicated with more dyadic relationships taken into consideration in the future. Although objectivity was a goal of the authors while analysing the interviews, there is an important research bias to be considered in this study. The authors were also participants of the study; our own feelings will have implicit subjectivity that may influence this case study, and our answers from the interview will have social desirability biases that should be accounted for.

Nonetheless, the study captured rich qualitative information for use by the reader, and it served its purpose to describe a mentor-mentee relationship within an accelerator such as EDUCATE. Future empirical research is highly recommended. The conclusions show the feasibility of integrating theoretical and mentorship research to analyse the interpersonal processes of the relationship. Furthermore, the mixed-method design can be of use to assess the mentorship relationship, exploring the links between 
theory and empirical results, challenging theoretical assumptions and developing new theories for the specific accelerator context (Östlund et al., 2011). Previous meta-analysis has shown the lack of empirical evidence in mentorship assessment and evaluation, showing only 10 per cent of studies with validated instruments, longitudinal approaches or direct observation (Linn et al., 2015). There is also a lack of experimental designs to assess effectiveness constructs of the relationship (Gershenfeld, 2014). Therefore, further production of research to start filling these gaps in the literature is encouraged, especially in the accelerator context, to improve the knowledge base for mentorship and produce empirical findings to examine the phenomenon as a dyadic relationship, and the interpersonal processes that take place within it.

\section{Notes on the contributors}

Santiago De Ossorno Garcia is a psychologist and researcher, with practitioner experience in mental health settings. His research focus has been in the field of bullying prevention and evaluation in schools using statistical modelling and ecological frameworks. He investigates psychological measures in digital environments and digital mental health interventions. He worked as a mentor using his expertise in social sciences and health methodologies to support SMEs in developing evidence for their products, services and solutions.

Luke Doyle is a software developer with a special interest in the education sector. He is a qualified teacher and the creator of SwopBots, a puzzle game that teaches basic coding concepts. As part of the EDUCATE project, he worked with school students to create CodeMe - an easily accessible online game creation tool. He is also the founder of CAFFE - a charity that teaches computing skills to young people in Bangladesh.

\section{References}

Abedin, Z., Biskup, E., Silet, K., Garbutt, J.M., Kroenke, K., Feldman, M.D. et al. (2012) 'Deriving competencies for mentors of clinical and translational scholars'. Clinical and Translational Science, 5 (3), 273-80. https://doi.org/10.1111/j.1752-8062.2011.00366.x.

Allen, T.D. and Eby, L.T. (2003) 'Relationship effectiveness for mentors: Factors associated with learning and quality'. Journal of Management, 29 (4), 469-86. https://doi.org/10.1016/S0149-2063_03_00021-7.

Allen, T.D., Eby, L.T. and Lentz, E. (2006) 'Mentorship behaviors and mentorship quality associated with formal mentoring programs: Closing the gap between research and practice'. Journal of Applied Psychology, 91 (3), 567-78. http://dx.doi.org/10.1037/0021-9010.91.3.567.

Argote, L. and Ingram, P. (2000) 'Knowledge transfer: A basis for competitive advantage in firms'. Organizational Behavior and Human Decision Processes, 82 (1), 150-69. https://doi.org/10.1006/ obhd.2000.2893.

Armstrong, S.J., Allinson, C.W. and Hayes, J. (2002) 'Formal mentoring systems: An examination of the effects of mentor/protégé cognitive styles on the mentoring process'. Journal of Management Studies, 39 (8), 1111-37. https://doi.org/10.1111/1467-6486.00326.

Bandura, A. (1997) Self-Efficacy: The exercise of control. New York: Freeman.

Blake-Beard, S.D., O'Neill, R.M. and McGowan, E. (2007) 'Blind dates? The importance of matching in successful formal mentoring relationships'. In B.R. Ragins and K.E. Kram (eds), The Handbook of Mentoring at Work. Thousand Oaks, CA: Sage, 617-32.

Bozionelos, N., Bozionelos, G., Polychroniou, P. and Kostopoulos, K. (2014) 'Mentoring receipt and personality: Evidence for non-linear relationships'. Journal of Business Research, 67 (2), 171-81. http://dx.doi.org/10.1016/j.jbusres.2012.10.007.

Chandler, D.E. and Ellis, R. (2011) 'Diversity and mentoring in the workplace: A conversation with Belle Rose Ragins'. Mentoring \& Tutoring: Partnership in Learning, 19 (4), 483-500. http://dx.doi.org/ 10.1080/13611267.2011.622082.

Chandler, D.E., Kram, K.E. and Yip, J. (2011) 'An ecological systems perspective on mentoring at work: A review and future prospects'. Academy of Management Annals, 5 (1), 519-70.

https://doi.org/10.5465/19416520.2011.576087. 
Chun, J.U., Litzky, B.E., Sosik, J.J., Bechtold, D.C. and Godshalk, V.M. (2010) 'Emotional intelligence and trust in formal mentoring programs'. Group and Organization Management, 35 (4), 421-55. https://doi.org/10.1177/1059601110378293.

Cohen, S. (2013) 'What do accelerators do? Insights from incubators and angels'. Innovations: Technology, Governance, Globalization, 8 (3-4), 19-25. http://dx.doi.org/10.1162/inov_a_00184.

Cohen, S. and Hochberg, Y. (2014) 'Accelerating startups: The seed accelerator phenomenon'. SSRN, 30 March. http://dx.doi.org/10.2139/ssrn.2418000.

Creswell, J.W., Plano Clark, V.L., Gutmann, M.L. and Hanson, W.E. (2003) 'Advanced mixed methods research designs'. In A. Tashakkori and C. Teddlie (eds), Handbook of Mixed Methods in Social and Behavioral Research. Thousand Oaks, CA: Sage, 209-40.

Cukurova, M., Luckin, R. and Clark-Wilson, A. (2019) 'Creating the golden triangle of evidenceinformed education technology with EDUCATE'. British Journal of Educational Technology, 50 (2), 490-504. https://doi.org/10.1111/bjet.12727.

Cunningham, J.B. (1993) 'Facilitating a mentorship programme'. Leadership and Organization Development Journal, 14 (4), 15-20. https://doi.org/10.1108/01437739310039442.

Dempwolf, C.S., Auer, J. and D'Ippolito, M. (2014) Innovation Accelerators: Defining characteristics among startup assistance organizations. Small Business Administration, Office of Advocacy. Accessed 20 November 2020. https://advocacy.sba.gov/2014/10/01/innovation-acceleratorsdefining-characteristics-among-startup-assistance-organization/.

Deutsch, N. and Spencer, R. (2009) 'Capturing the magic: Assessing the quality of youth mentoring relationships'. New Directions in Youth Development: Theory, Practice and Research, 121, 47-70. https://doi.org/10.1002/yd.296.

Eby, L.T.D.T., Allen, T.D., Hoffman, B.J., Baranik, L.E., Sauer, J.B., Baldwin, S., Morrison, M.A., Kinkade, K.M., Maher, C.P., Curtis, S. and Evans, S.C. (2013) 'An interdisciplinary meta-analysis of the potential antecedents, correlates, and consequences of protégé perceptions of mentoring'. Psychological Bulletin, 139 (2), 441-76. http://dx.doi.org/10.1037/a0029279.

Erdem, F. and Aytemur, J.Ö. (2008) 'Mentoring - a relationship based on trust: Qualitative research'. Public Personnel Management, 37 (1), 55-65. https://doi.org/10.1177/009102600803700104.

Fereday, J. and Muir-Cochrane, E. (2006) 'Demonstrating rigor using thematic analysis: A hybrid approach of inductive and deductive coding and theme development'. International Journal of Qualitative Methods, 5 (1), 80-92. https://doi.org/10.1177/160940690600500107.

Fishback, B., Gulbranson, C.A., Litan, R.E., Mitchell, L. and Porzig, M. (2007) 'Finding business idols: A new model to accelerate start-ups'. SSRN, July. http://dx.doi.org/10.2139/ssrn.1001926.

Forsbach-Rothman, T. (2007) 'The mentor role: Is training necessary?'. Journal of In-service Education, 33 (2), 245-7. https://doi.org/10.1080/13674580701293135.

Fowler, J. and O'Gorman, J.G. (2005) 'Mentoring functions: A contemporary view of the perceptions of mentees and mentors'. British Journal of Management, 16 (1), 51-7. https://doi.org/10.1111/ j.1467-8551.2005.00439.x.

Gaba, V. and Meyer, A.D. (2008) 'Crossing the organizational species barrier: How venture capital practices infiltrated the information technology sector'. Academy of Management Journal, 51 (5), 976-98. https://doi.org/10.5465/amj.2008.34789671.

Gehrke, N.J. and Kay, R.S. (1984) 'The socialization of beginning teachers through mentor-protégé relationships'. Journal of Teacher Education, 35 (3), 21-4. https://doi. org/10.1177/002248718403500305.

Germain, M.L. (2011) 'Formal mentoring relationships and attachment theory: Implications for human resource development'. Human Resource Development Review, 10 (2), 123-50. https://doi.org/10.1177/1534484310397019.

Gershenfeld, S. (2014) 'A review of undergraduate mentoring programs'. Review of Educational Research, 84 (3), 365-91. https://doi.org/10.3102/0034654313520512.

Gormley, B. (2008) 'An application of attachment theory: Mentoring relationship dynamics and ethical concerns'. Mentoring \& Tutoring: Partnership in Learning, 16 (1), 45-62. https://doi. org/10.1080/13611260701800975.

Greene, J.C., Caracelli, V.J. and Graham, W.F. (1989) 'Toward a conceptual framework for mixedmethod evaluation designs'. Educational Evaluation and Policy Analysis, 11 (3), 255-74. https://doi.org/10.2307/1163620.

Hall, K.M., Draper, R.J., Smith, L.K. and Bullough Jr, R.V. (2008) 'More than a place to teach: Exploring the perceptions of the roles and responsibilities of mentor teachers'. Mentoring and Tutoring, 16 (3), 328-45. https://doi.org/10.1080/13611260802231708.

Hamlin, R.G. and Sage, L. (2011) 'Behavioural criteria of perceived mentoring effectiveness: An empirical study of effective and ineffective mentor and mentee behaviour within formal mentoring relationships'. Journal of European Industrial Training, 35 (8), 752-78. https://doi. org/10.1108/03090591111168311. 
Handelsman, J., Pfund, C., Lauffer, S.M. and Pribbenow, C.M. (2005) Entering Mentoring. Madison: The Wisconsin Program for Scientific Teaching. Accessed 22 January 2021. https:// undergradresearch.illinois.edu/assets/docs/OUR_Faculty_Mentoring.pdf.

Hobson, A.J., Ashby, P., Malderez, A. and Tomlinson, P.D. (2009) 'Mentoring beginning teachers: What we know and what we don' $\mathrm{t}^{\prime}$. Teaching and Teacher Education: An International Journal of Research and Studies, 25 (1), 207-16. http://dx.doi.org/10.1016/j.tate.2008.09.001.

Hofman, M. (1998) 'Mentoring Programs'. Inc., 1 June. Accessed 25 November 2020. www.inc.com/ articles/1998/06/14570.html.

Hutchinson, A., Rawson, H., O’Connell, B., Walker, H., Bucknall, T., Forbes, H., Ostaszkiewicz, J. and Ockerby, C. (2017) 'Tri-focal model of care implementation: Perspectives of residents and family'. Journal of Nursing Scholarship, 49 (1), 33-43. https://doi.org/10.1111/jnu.12269.

Kaplan, S.A. and Garrett, K.E. (2005) 'The use of logic models by community-based initiatives'. Evaluation and Program Planning, 28 (2), 167-72. https://doi.org/10.1016/j. evalprogplan.2004.09.002.

King, N. (2012) 'Doing template analysis'. In G. Symon and C. Cassell (eds), Qualitative Organizational Research. London: Sage, 426-50.

Kram, K.E. (1980) 'Mentoring processes at work: Developmental relationships in managerial careers'. Dissertation Abstracts International, 41, 05B (UMI No. 8025206).

Kram, K.E. (1983) 'Phases of the mentoring relationship'. Academy of Management Journal, 26 (4), 608-25. https://doi.org/10.5465/255910.

Kram, K.E. (1988) Mentoring at Work: Developmental relationships in organizational life. Glenview, IL: University Press of America.

Lagrange, J.B., Artigue, M., Laborde, C. and Trouche, L. (2001, July) 'A meta study on IC technologies in education: Towards a multidimensional framework to tackle their integration'. In PME CONFERENCE, Vol. 1, 1-111. Accessed 23 November 2020. https://www.academia. edu/2744181/A_meta_study_on_IC_technologies_in_education_Towards_a_multidimensional_ framework_to_tackle_their_integration.

Laverack, G. and Wallerstein, N. (2001) 'Measuring community empowerment: A fresh look at organizational domains'. Health Promotion International, 16 (2), 179-85. https://doi.org/10.1093/ heapro/16.2.179.

Lewin, K. (1947) Field Theory in Social Science. New York: Harper \& Row.

Linn, M.C., Palmer, E., Baranger, A., Gerard, E. and Stone, E. (2015) 'Undergraduate research experiences: Impacts and opportunities'. Science, 347 (6222), 1261757. https://doi.org/10.1126/ science.1261757.

Lunsford, L.G., Crisp, G., Dolan, E.L. and Wuetherick, B. (2017) 'Mentoring in higher education'. The SAGE Handbook of Mentoring, 20, 316-34. http://dx.doi.org/10.4135/9781526402011.

MacArthur, J. (2014) 'The role of mentors in integrating research and practice'. Journal of Integrated Care, 22 (3), 117-22. https://doi.org/10.1108/JICA-04-2014-0016.

Mejia, J. and Gopal, A. (2015) 'Now and later? Mentorship, investor ties and new venture performance in entrepreneurial seed-accelerators'. Paper presented at DRUID Conference, Rome, 15-17 June. Accessed 23 November 2020. https://conference.druid.dk/acc_papers/ kvkoblkf64j28g3eqccmfsko2q5m.pdf.

Menges, C. (2016) 'Toward improving the effectiveness of formal mentoring programs: Matching by personality matters'. Group \& Organization Management, 41 (1), 98-129. https://doi.org/ 10.1177/1059601115579567.

Millar, A., Simeone, R.S. and Carnevale, J.T. (2001) 'Logic models: A systems tool for performance management'. Evaluation and Program Planning, 24 (1), 73-81. https://doi.org/10.1016/S01497189(00)00048-3.

Miller, P. and Bound, K. (2011) The Startup Factories: The rise of accelerator programmes to support new technology ventures. London: NESTA. Accessed 23 November 2020. https://media.nesta. org.uk/documents/the_startup_factories_0.pdf.

Moyer, A., Verhovsek, H. and Wilson, V.L. (1997) 'Facilitating the shift to population-based public health programs: Innovation through the use of framework and logic model tools'. Canadian Journal of Public Health, 88 (2), 95-8. https://doi.org/10.1007/BF03403869.

Mullen, E.J. (1994) 'Framing the mentoring relationship as an information exchange'. Human Resource Management Review, 4 (3), 257-81. https://doi.org/10.1016/1053-4822(94)90015-9.

Nottingham, S.L., Mazerolle, S.M. and Barrett, J.L. (2017) 'Effective characteristics of formal mentoring relationships: The National Athletic Trainers' Association Foundation research mentor program'. Athletic Training Education Journal, 12 (4), 244-55. https://doi.org/10.4085/1204244.

O'Connell, B. (2011) Start X: Training ground for Stanford's best and brightest. Kauffman Foundation.

Östlund, U., Kidd, L., Wengstrom, Y. and Rowa-Dewar, N. (2011) 'Combining qualitative and quantitative research within mixed method research designs: A methodological 
review'. International Journal of Nursing Studies, 48 (3), 369-83. https://doi.org/10.1016/j. ijnurstu.2010.10.005.

Pauwels, C., Clarysse, B., Wright, M. and Van Hove, J. (2016) 'Understanding a new generation incubation model: The accelerator'. Technovation, 50-1 (1), 13-24. https://doi.org/10.1016/j. technovation.2015.09.003.

Pfund, C. (2016) 'Studying the role and impact of mentoring on undergraduate research experience'. Paper commissioned for the Committee on Strengthening Research Experiences for Undergraduate STEM Students. National Academics of Sciences, Teaching, Engineering and Medicine. Accessed 23 November 2020. https://sites.nationalacademies.org/cs/groups/ dbassesite/documents/webpage/dbasse_177287.pdf.

Pfund, C., Byars-Winston, A., Branchaw, J., Hurtado, S. and Eagan, K. (2016) 'Defining attributes and metrics of effective research mentoring relationships'. AIDS and Behavior, 20 (2), 238-48. https://doi.org/10.1007/s10461-016-1384-z.

Ragins, B.R. and Cotton, J.L. (1999) 'Mentor functions and outcomes: A comparison of men and women in formal and informal mentoring relationships'. Journal of Applied Psychology, 84 (4), 529-50. http://dx.doi.org/10.1037/0021-9010.84.4.529.

Ragins, B.R. and Kram, K.E. (2007) 'The roots and meaning of mentoring'. In B.R. Ragins and K.E. Kram (eds), The Handbook of Mentoring at Work: Theory, research, and practice. Thousand Oaks, CA: Sage, 3-15.

Rippon, J. and Martin, M. (2003) 'Supporting induction: Relationships count'. Mentoring and Tutoring, 11 (2), 211-26. http://dx.doi.org/10.1080/13611260306858.

Roblyer, M.D. and Knezek, G.A. (2003) 'New millennium research for educational technology: A call for a national research agenda'. Journal of Research on Technology in Education, 36 (1), 60-71. https://doi.org/10.1080/15391523.2003.10782403.

Scandura, T.A. and Pellegrini, E.K. (2004) 'Competencies of building the developmental relationship'. In D. Clutterback and G. Lane (eds), The Situational Mentor: An international review of competencies and capabilities in mentoring. Oxford: Gower, 83-93.

Scandura, T.A. and Ragins, B.R. (1993) 'The effects of sex and gender role orientation on mentorship in male-dominated occupations'. Journal of Vocational Behavior, 43 (3), 251-65. https://doi.org/10.1006/ jvbe.1993.1046.

Scandura, T.A. and Williams, E.A. (2001) 'An investigation of the moderating effects of gender on the relationships between mentorship initiation and protégé perceptions of mentoring functions'. Journal of Vocational Behavior, 59 (3), 342-63. https://doi.org/10.1006/jvbe.2001.1809.

Schrum, L., Thompson, A., Sprague, D., Maddux, C., McAnear, A., Bell, L. and Bull, G. (2005) 'Advancing the field: Considering acceptable evidence in educational technology research'. Contemporary Issues in Technology and Teacher Education, 5 (3), 202-9. Accessed 20 November 2020. www.learntechlib.org/primary/p/21841/.

Seibert, S. (1999) 'The effectiveness of facilitated mentoring: A longitudinal quasi-experiment'. Journal of Vocational Behavior, 54 (3), 483-502. https://doi.org/10.1006/jvbe.1998.1676.

Stokes, P. (2003) 'Exploring the relationship between mentoring and counselling'. British Journal of Guidance and Counselling, 31 (1), 25-38. https://doi.org/10.1080/0306988031000086143.

Thiry, H. and Laursen, S.L. (2011) 'The role of student-advisor interactions in apprenticing undergraduate researchers into a scientific community of practice'. Journal of Science Education and Technology, 20 (6), 771-84. https://doi.org/10.1007/s10956-010-9271-2.

Turban, D.B. and Lee, F.K. (2007) 'The role of personality in mentoring relationships: Formation, dynamics, and outcomes'. In B.R. Ragins and K.E. Kram (eds), The Handbook of Mentoring at Work. Thousand Oaks, CA: Sage, 21-50.

Wanberg, C.R., Welsh, E.T. and Hezlett, S.A. (2003) 'Mentoring research: A review and dynamic process model'. In J.J. Martocchio and G.R. Ferris (eds), Research in Personnel and Human Resources Management, Vol. 22. Amsterdam: Elsevier, 39-124.

W.K. Kellogg Foundation (2004) Logic Model Development Guide. Battle Creek, MI: W.K. Kellogg Foundation.

Yitshaki, R. and Drori, I. (2018) 'Understanding mentorship processes'. In M. Wright and I. Drori (eds), Accelerators: Successful venture creation and growth. Cheltenham: Edward Elgar Publishing, 58-80.

Zachary, L.J. (2002) 'The role of teacher as mentor'. New Directions for Adult and Continuing Education, 93, 27-38. https://doi.org/10.1002/ace.47.

Zhao, Y., Yan, B. and Lei, J. (2008) 'The logic and logic model of technology evaluation'. In J. Voogt and G. Knezek (eds), International Handbook of Information Technology in Primary and Secondary Education. Boston: Springer, 633-53. 